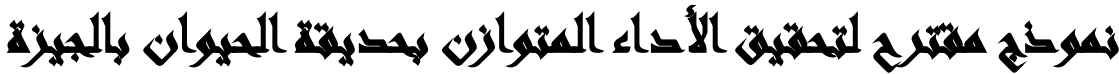

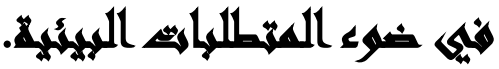

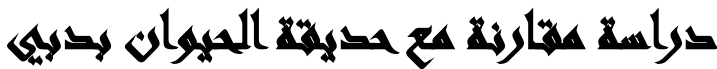

\section{[1 $\leqslant]$}

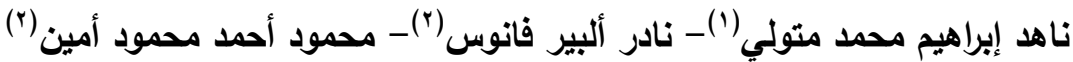

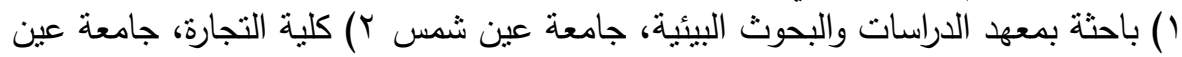

\section{كالمسريطل}

قد يكون تغيير المناخ ذو تأثير كبير بالنسبة للنتوع البيولوجي، وتهنم حدائق الحيوانات

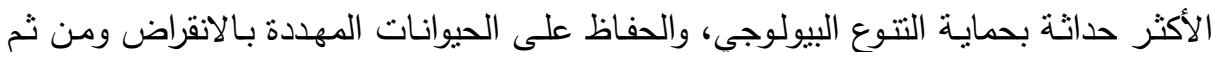

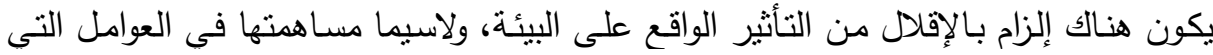

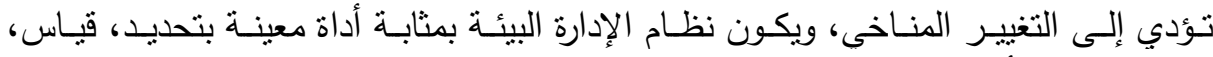

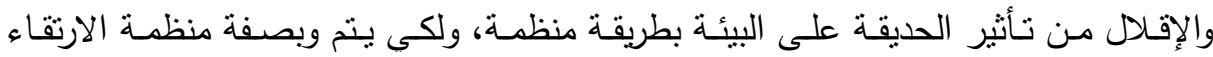

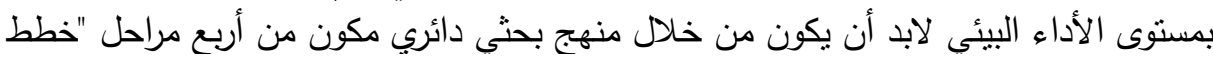

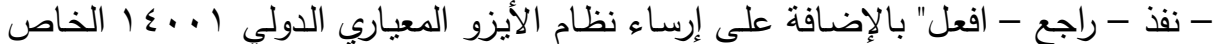

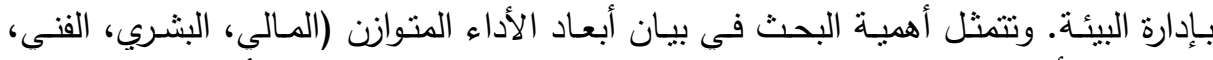

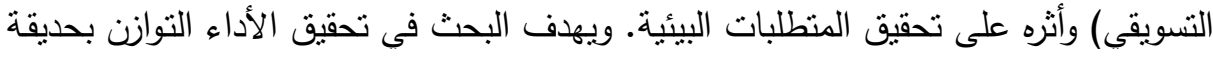

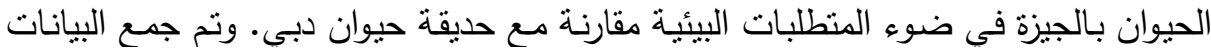

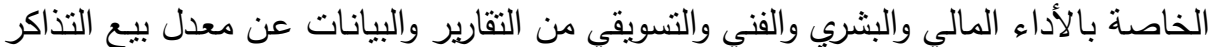

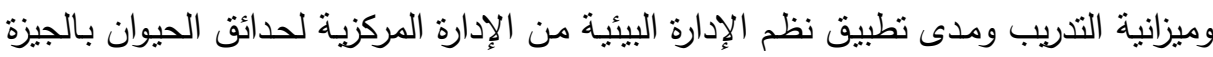

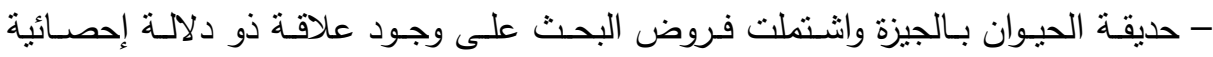

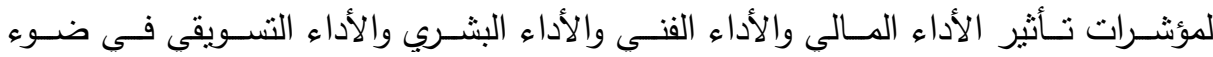

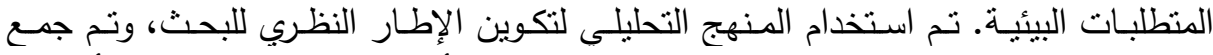

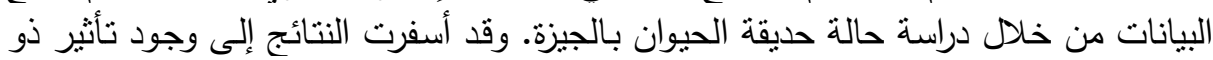

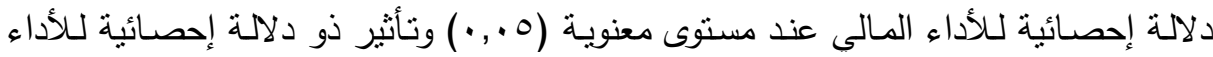

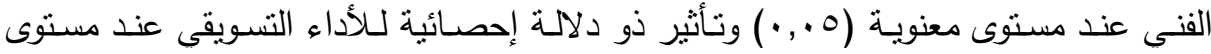
عفوية (0.. •) وقد أوصى البحث بعمل البرامج التدريبية للعاملين على تطبيق نظام الإدارية 


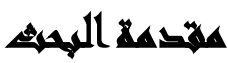

قد يكون تغيير المناخ ذو تأثير كبير بالنسبة للتنوع البيولوجي، وتهتم حدائق الحيوانات

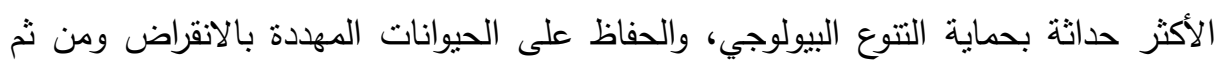

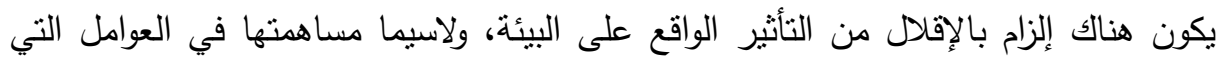

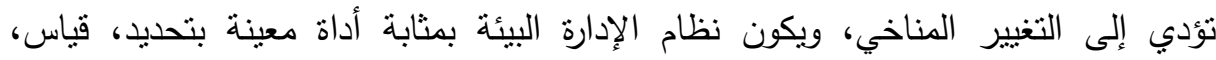

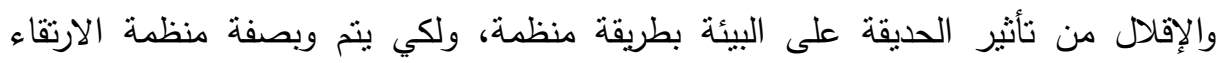

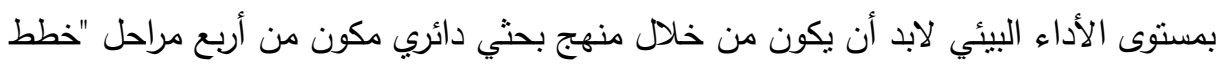

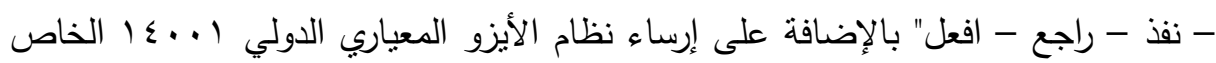

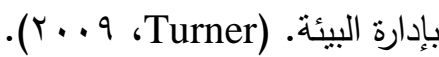

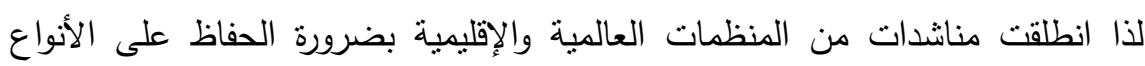

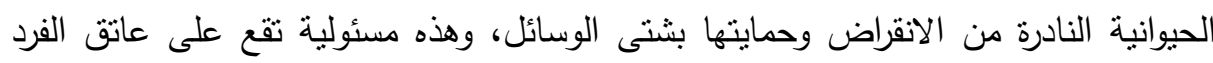
أينما كان وليس على المنظمات الدهتمة بالحيوانات فقط. لذلك صارت حدائق الحيوان وسيلة حماية لا بديل عنها للحيوانات المهددة بالانقراض. وفي العقود القليلة العاضية، غبرت حدائق الحيوان حول العالم من نفسها، فهي لم لم تعد مقصداً

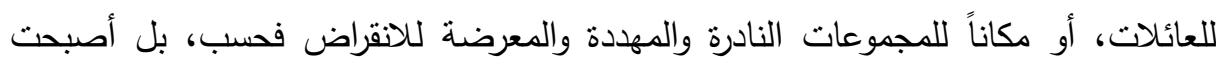
أيضاً منظمات بحثية تضع البحث العلمي والمحافظة على الأنواع في صميم اهتمامها. (Y.17 ، zhu, y;)

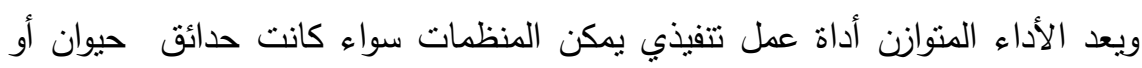

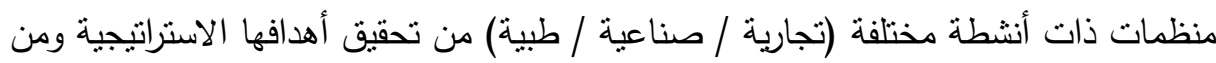
تقييم أدائها التثتيلي والمالي والبيئي وفق إطار متكامل من المقاييس المالية وغير المالية

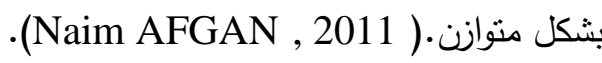

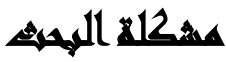

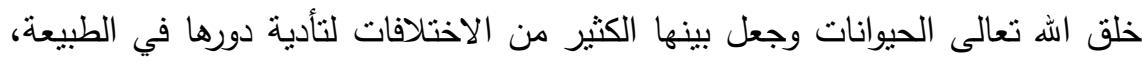

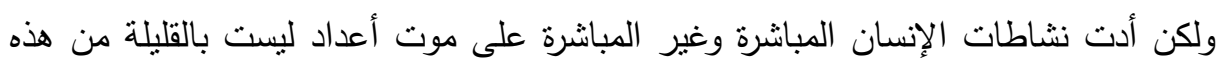

$$
\text { المجلد السادس والأربعون، الجزء الثاني، يونيه } 9 \text { ـ ب }
$$


الحيوانات، فبعض الأنواع قد انقرض فعلاً، وبعضها مهدد بالانقراض وهذا قد يؤدي إلى خلل في النظام البيئي إذا لم يسارع الإنسان إلى حمايتها والتقليل من الأخطار الواقعة عليها.

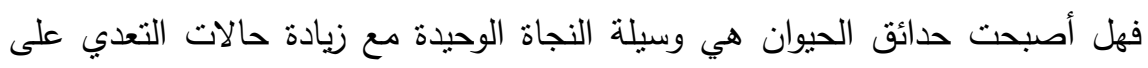

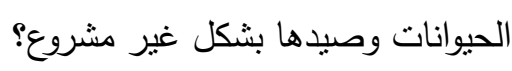

أم أن حتى هذه الحدائق تمنل تعذيباً للحيوانات التي تعيش حبيسة فئهات فئها كما تقول بعض

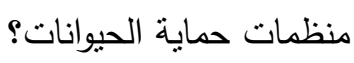
وتتمنل مشكلة البحث في كيفية تحقيق الأداء المتوازن بالحديقة وفق احتباجاتها الاستراتيجية واستخدام الأساليب الحديثة لتحقيق الأداء المتوازن بأبعاده في ضوء الأدئ المنطلبات البيئية. وذلك من خلال المقابلة الثخصية مع بعض القيادات وبعض العاملين (والأطباء البيطريين - إداريين - فنيين) في حديقة الحيوان بالجيزة، والاطلاع على التقارير التي تصدرها

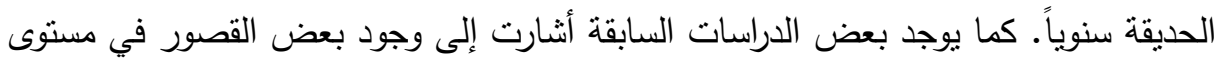

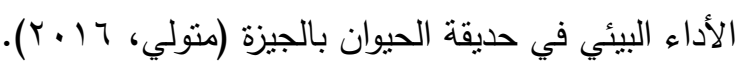

\section{تحساولاهي المهمه}

وفي ضوء ما سبق نطرح الدراسة مجموعة من التساؤلات التالية: أ- ما مدى نأثير مؤثرات تحقيق الأداء المالي على مؤى مؤشرات الأداء الأخرى في ضواء

$$
\text { المتطلبات البيئية فى حديقة الحيوان؟ }
$$

ب- ما مدى تأثثر مؤشرات تحقيق الأداء البشري على مؤشرات الأداء الأخرى في ضوء

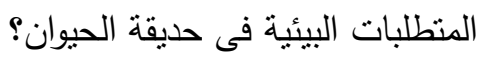

ج-ما مدى تأثير مؤشرات تحقيق الأداء الفني على مؤشرات الأداء الأخرى في ضوء المنطلبات البيئية فى حديقة الحيوان؟

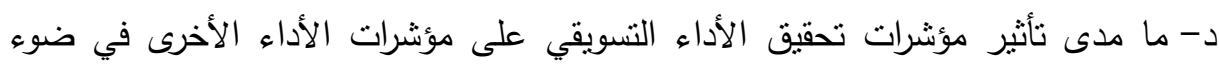

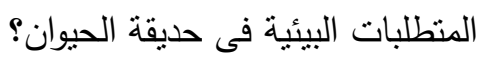

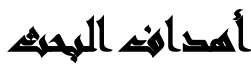


تحاول الباحثة من تلك الدراسة تحقيق الأهداف الآتية: • الهدف الرئيسي: نموذج مقترح لتحقيق الأداء المتوازن بحديقة الحيوان بالجيزة في ضواء الأي

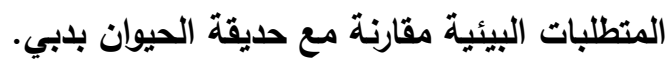
• الأهداف الفرعية:

أ- دراسة وتحليل الأداء المنوازن (المالي/ البشري/ الفني/ النسويقي) في ضوء المنطلبات البيئية بحديثة الحيوان بالجيزة.

ب- وضع تصور مستقبلي لكيفية ضمان تحقيق الأداء المتوازن في ضوء المتطلبات البيئية لحديقة الحيوان بالجيزة.

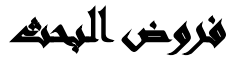

أ- لا يوجد تأثثر معنوي لمؤشرات تحقيق الأداء المالي على مؤشرات الأداء الأخرى في ضوء المتطلبات البيئية بحديقة الحيوان بالجيزة.

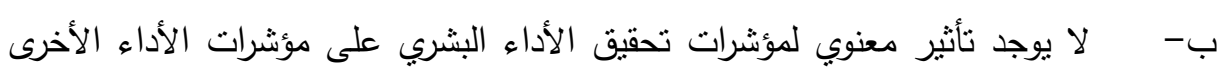
في ضوء المنطلبات البيئية بحديقة الحيوان بالجيزة.

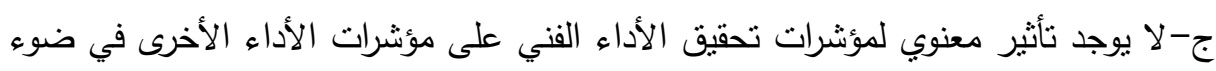
المتطلبات البيئية بحديقة الحيوان بالجيزة. د- لا يوجد تأثثر معنوي لمؤشرات تحقيق الأداء النسويقي على مؤشرات الأداء الأخرى في بأي ضوء المتطلبات البيئية حديقة الحيوان بالجيزة. 


\section{كتغنيرايت المبهم}

$$
\begin{aligned}
& \text { • المتغير المستقل. } \\
& \text { - الأداء المالي. } \\
& \text { - الأداء البشري. } \\
& \text { - الأداء الفني. } \\
& \text { - الأداء التسويقي. } \\
& \text { • المتغير التابع }
\end{aligned}
$$

- منطلبات الإدارة البيئية.

\section{مشوت الهمشي}

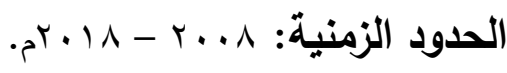

الحدود المكانية: داخل حديقة الحيوان بالجيزة

\section{منهمج المهشه}

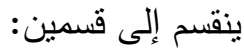

القسم الأول: المنهج الاستقرائي: حيث اعتمد البحث على المنهج الاستقرائي في إعداد الإطار النظري للبحث وصياغة مشكلة وفروض البحث وذلك من خلال استقراء ما أمكن التوصل إليه من المراجع العلمية العربية والأجنبية في مجال تحقيق الأداء البيئي ومنطلبات الإدارة البيئية في حدائق الحيوان.

القسم الثاني: المنهج القياسي: اعتمدت الدراسة على أسلوب الوصف القياسي واعتمدت على المصادر الآتية: - مان أ - مصادر ثانوية: استخدام المراجع والمصادر المتوفرة في المكتبات وذلك لبناء الإطار النظري لهذه الدراسة ومنها الكتب والدراسات السابقة والمقالات العربية والأجنبية. ب - مصادر أولية: دراسة حالة على حديقة الحيوان بالجيزة. 


\section{الإطار اللنظليه}

\section{مصطلحات البحث:}

أ- الأداء البيئي: هو كل النشاطات والعمليات التي تقوم في المنظمة سواء بشكل إجباري

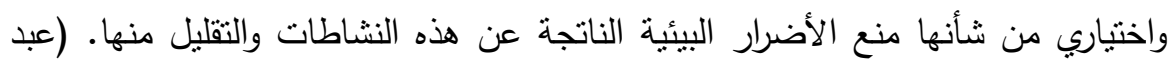

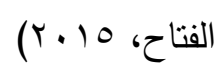

ب- الأداء المالي: إن الأداء المالي هو بما تحققه المنظمة من عائدات يلخصها سجل حسابي ستتد إلى قياس السياسات، والعمليات المرتبطة بالإطار المالي للمنظمة ضمن فن فنرة

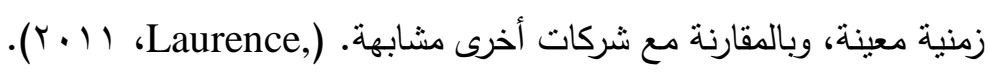
ج- الأداء المرتبط برضا العميل: يمكن معرفة أداء المنظمة لهذا المنظور من خلادل استبيان

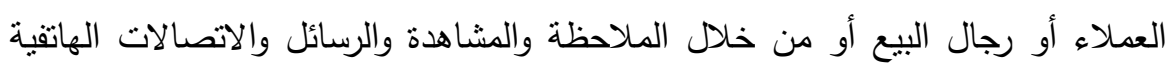
والتغذية العكسية وحجم المبيعات المتحقق باعتماد مقاييس هذا المنظور • (الحنيطي،

د- الأداء المرتبط بتحسين وتطوير العمليات الداخلية: يقصد به عملية تحويل المدخلات

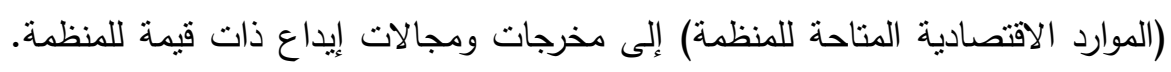

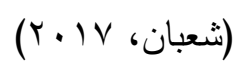

هـ الأداء المرتبط بالنمو والتعليم للعاملين: يشمل مفهوم الأداء المنوازن للمنظمات على الألى الأداء والمرنبط بالنمو والتعلم للعاملين، وذللك حسب ما ذكر (كابلان ونورتون) حيث اهتم في هذا المجال بثلاثة محاور أساسية هي: المحور الأول : قدرات العاملين. المحور الثاني: قدرات نظم المعلومات.

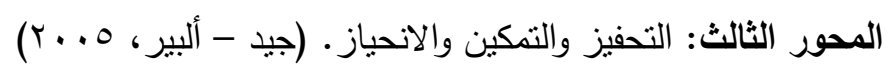

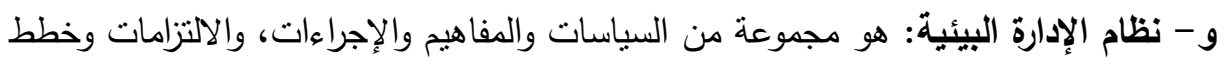
العمل التي من شأنها منع حدوث عناصر التلوث البيئي بأنواعه، وتقهم العاملين في

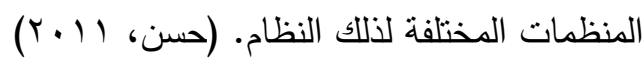




\section{التراسايش الماريش}

أ) الاراسات العربية:

- - دراسة (مطر - 10 ـ r): يتمنل الهذف الرئيسي لهذه الدراسة محاولة السعي لتحسين الأداء البيئي من خلال نظام التكاليف على أساس النشاط وبطاقة التقويم المنوازن للأداء في الثركات المؤثرة في البيئة بشكل سلبي. أهم النتائج: وجود علاقة جوهرية ارتباطية دالة إحصائيا عند مستوى دلالة ال.,., بمقابل

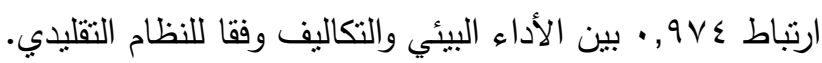
r - دراسة (متولي - 1 - ـ ץ): اهتمت هذه الدراسة بتفعيل النظم الإدارية بحديقة حيوان الجيزة وتحديد أوجه القصور في مستوى الأداء البيئي والرقابة البيئية. أهم النتائج: توصلت هذه الدراسة إلى وجود علاقة ارتباطية ذات دلالة معنوية بين تفعيل النظم الإدارية في حديقة الحيوان بالجيزة وتحقيق الإدارة البيئية. ب) - الدراسات الأجنبية: - دراسة . Wang, L (2006): تهدف الدراسة إلى أهمية دراسة كفاءة أداء المنشأة عن طريق منهج شمولية البيانات ومنهج القياس المنوازن للأداء. أهم النتائج: تمثلت أهم نتائج التحليل منهج القياس المتوازن للأداء في أهمية بعد البحوث

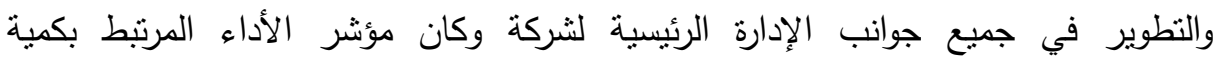

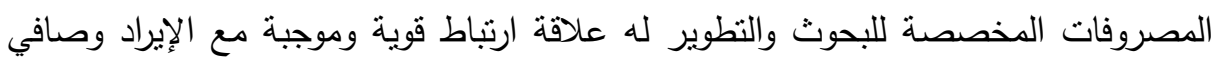
المبيعات للمشترين الرئيسيين. r- دراسة A. Mallapur \& A. Ramanathan (2009): نم إجراء مسح استبياني

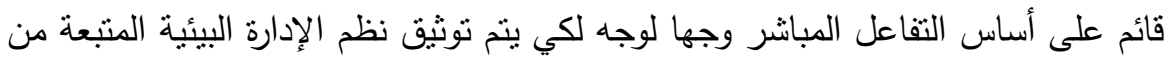
جانب • ( منشآت معنية بتربية ورعاية الفيل الآسيوي في الهند.

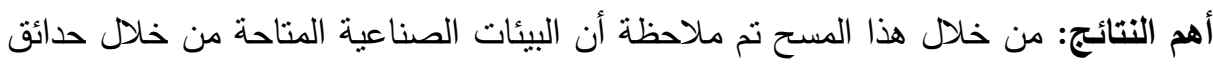
الحيوانات والغابات في الهند كانت أكثر ملائمة بالنسبة للأفيال وذللك مقارنة بالظروف الستات السائدة في المعابد والمعسكرات السياحية. 
r- دراسة Zhu, Y., Gvo, D., Wang, D., Lij بالتحليل للأمراض المعدية حيوانية المصدر ومدى الضرر في حالة انتشاره داخل حدائق الحيوان.

أهم النتائج : توصلت هذه الدراسة إلى أنه لكي نمنع المرض ونحكم السيطرة عليه بفاعلية من الضروري الكثف عن النشوء المرضي والنعرف على العوامل المؤثرة لحدوثه.

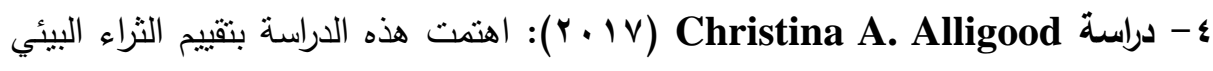
في حديثة الحيوان (فلوريدا) وقياس مستوى أداء الموظفين عقب العملية التعليمية المعنية بالتدريب على رعاية الحيوان ومدى تتفيذ استراتيجيات الثراء البيئي مثل استراتيجية الأمان المهني.

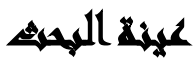

حديقة الحيوان بالجيزة

\section{إلجراعائ المهيث}

أداة الدراسة: نم جمع البيانات الخاصة بالأداء المالي والبشري والفني والتسويقي من الثقارير والبيانات عن معدل بيع التذاكر وميزانية التنريب ومدى تطبيق نظم الإدارة البيئية من الإدارة المركزية لحدائق الحيوان بالجيزة - حديقة الحيوان بالجيزة. تم جمع البيانات الخاصة بالتحليل الإحصائي من حديقة حيوان الجيزة وتحليلها إحصائياً عن طريق البرنامج الإحصائي المعروف برنامج الحزم الإحصائية معنوية للعلوم الاجتماعية Statistical Package For Social Sciences الآلي من خلال برنامج الحزم الإحصائية SPSS V. 23 ونم تفريغ البيانات- خطوة تمهيدية لتبويب البيانات وتحليلها، ومن خلاله نم تحليل الانحدار البسيط لدراسة تأثير المتغيرات

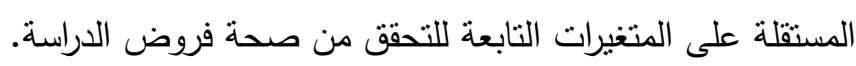




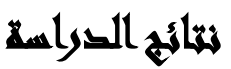

الفرض الأول: لا يوجد تأثير معنوي ذو دلالة إحصائية لمؤشرات تحقيق الأداء المالي

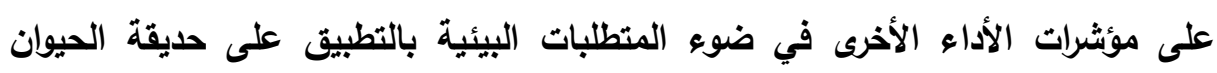
بالجيزة. جدول (1): اختبار الإنحدار لتأثنر معدل مبيعات التذاكر على الأداء المالي

\begin{tabular}{|c|c|c|c|c|c|c|c|c|}
\hline المعنوية & قيمة ف & المعياري & $\mathbf{R}$ & $\mathbf{R}^{2}$ & المعنوية & قيمة ت & قيمة بيتا & المتغيرات \\
\hline \multirow[b]{2}{*}{$\cdot, \cdots 7$} & \multirow[b]{2}{*}{$171, \wedge 17$} & \multirow[b]{2}{*}{$1,19 r$} & \multirow[b]{2}{*}{$\cdot, 99 \leq$} & \multirow[b]{2}{*}{$\cdot, 9 \wedge \wedge$} & $\cdot, \cdot r$ & ד, ד & 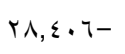 & الثابت \\
\hline & & & & & $\cdot, \cdots 7$ & $|r, V Y|$ & $19, \vee \uparrow \wedge$ & معدل مبيعات \\
\hline
\end{tabular}

يتبين من الجدول السابق وجود علاقة ارتباطية ذات دلالة إحصائية بين معدل مبيعات

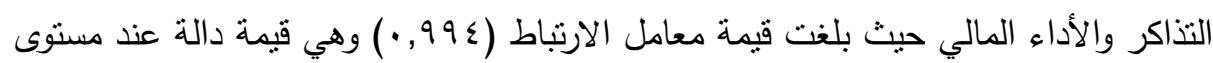
معنوية (0. • •) واقتراب معامل الارتباط من الواحد الصحيح بدل على قوة هذه العلاقة. بلغ معامل التحديد

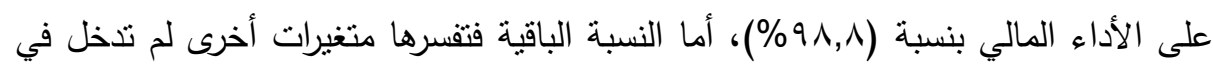

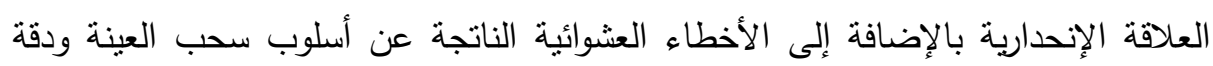

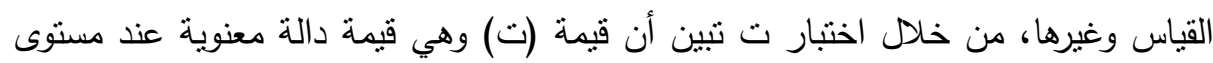

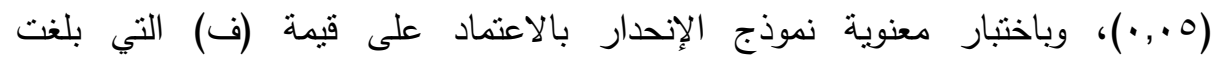

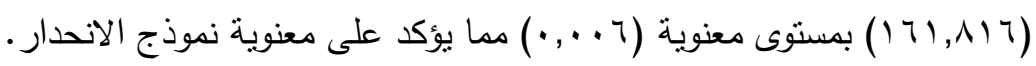

$$
Y=(-28.406)+19.728 X
$$

مما سبق نرفض الفرض الأول العدمي: لا يوجد تأثثير معنوي لمؤشرات تحقيق الأداء

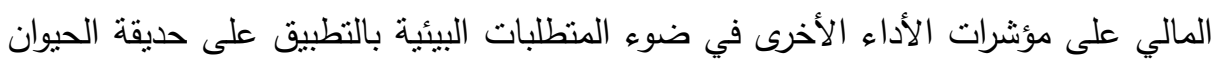
بالجيزة. 
ونقبل الفرض الأول البديل: يوجد تأثير معنوي ذو دلالة إحصائية لمؤشرات تحقيق الأداء

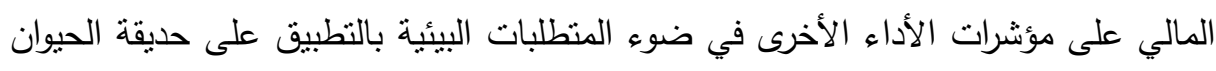
بالجيزة.

الفرض الثاني: لا يوجد تأثير معنوي لمؤشرات تحقيق الأداء البشري على مؤشرات الأداء الأخرى في ضوء المتطلبات البيئية بالتطبيق على حديقة الحيوان بالجيزة.

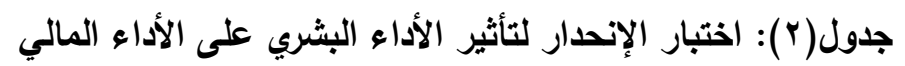

\begin{tabular}{|c|c|c|c|c|c|c|c|c|}
\hline المعنوية & قيمة & المعياري & $\mathbf{R}$ & $\mathbf{R}^{2}$ & المعنوية & قيمة & قيمة بيتا & المتغيرات \\
\hline \multirow[b]{2}{*}{$\cdot, .0$} & \multirow[b]{2}{*}{$r, 10 \leq$} & \multirow[b]{2}{*}{$\leqslant \neg \wedge \backslash \wedge \neg \Sigma, 1$} & \multirow[b]{2}{*}{$\cdot, 00 \mathrm{~V}$} & \multirow[b]{2}{*}{. TוI } & $\cdot, \ldots)$ & $7, .1 \leqslant$ & 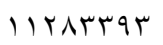 & الثابت \\
\hline & & & & & $\cdot, \ldots 1$ & $r, Y V Y$ & -,$\leqslant 10$ & البشري \\
\hline
\end{tabular}

يتبين من الجدول السابق وجود علاقة ارتباطية ذات دلالة إحصائية بين الأداء البشري

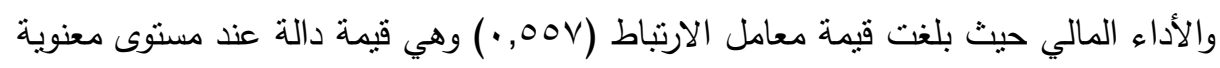
$\cdot(\cdot, \cdot 0)$

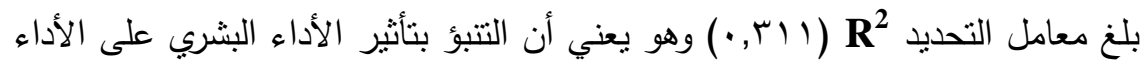

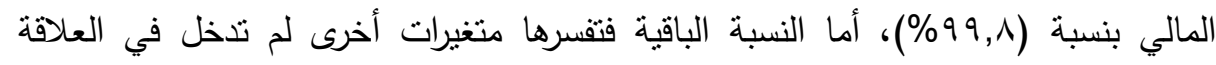
الإنحدارية بالإضافة إلى الأخطاء العشوائية الناتجة عن أسلوب سحب العبه العينة ودقة القياس وغيرها، من خلال اختبار ت تبين أن قيمة (ت) وهي قيمة دالة معنوية عند مستوى (0. ., ))،

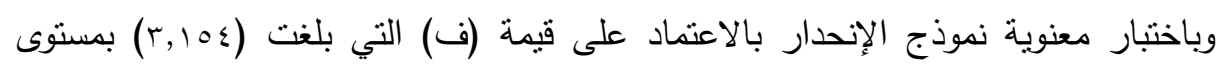
معنوية (0. . • · ) مما يؤكد على معنوية نموذج الانحدار . $Y=11283392.970+0.415 X$ جدول(ץ): اختبار الإنحدار لتأثثر الأداء البشري على الأداء الفني

\begin{tabular}{|c|c|c|c|c|c|c|c|c|}
\hline المعنوية & قيمة ف & المعياري & $\mathbf{R}$ & $\mathbf{R}^{2}$ & المعنوية & قيمة ت & قبيتا & المتغيرات \\
\hline \multirow[b]{2}{*}{$\cdot, \ldots)$} & \multirow[b]{2}{*}{$7 \leqslant, 79 \vee$} & \multirow[b]{2}{*}{$r \leqslant 9,01$} & \multirow[b]{2}{*}{$\cdot, Y V V$} & \multirow[b]{2}{*}{$\cdot, \cdot V V$} & $\cdot,, \cdot 1$ & צ & גזr, & الثابت \\
\hline & & & & &,,,$\cdot 1$ & $\Lambda, \cdot \leq r-$ & - & البشري \\
\hline
\end{tabular}


يتبين من الجدول السابق وجود علاقة ارتباطية ذات دلالة إحصائية بين الأداء البشري

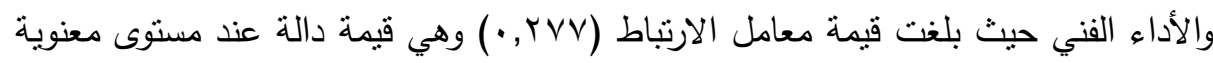
$\cdot(\cdot, \cdot 0)$

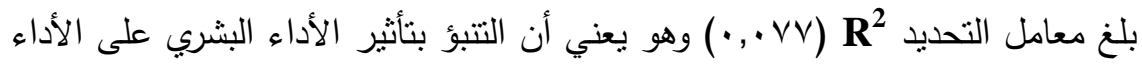

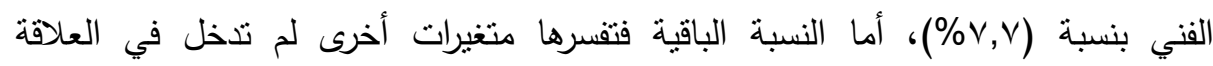

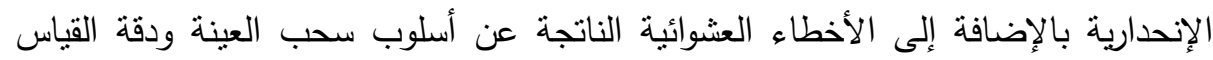
وغيرها، من خلال اختبار ت تبين أن قيمة (ت) وهي قيمة دالة معنوية عند مستوى (0. . •)،

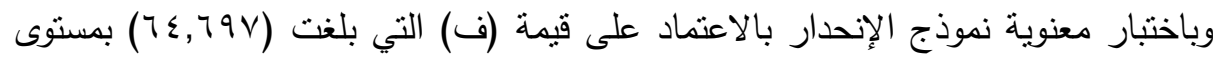

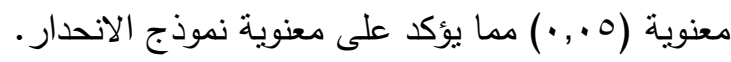
$Y=4.338+(-0.321) \quad X$ جدول (ع): اختبار الإنحدار لتأثثر الأداء البشري على الأداء التسويقي

\begin{tabular}{|c|c|c|c|c|c|c|c|c|}
\hline المعنوية & فيمة & الخطأ & $\mathbf{R}$ & $\mathbf{R}^{2}$ & المعنوية & قيمة ت & قيتمة & المتغيرات \\
\hline \multirow[b]{2}{*}{$\cdot, \ldots l$} & \multirow[b]{2}{*}{$\varepsilon r, \mid \vee$} & \multirow[b]{2}{*}{ •, TV. } & \multirow[b]{2}{*}{ גוr, } & \multirow[b]{2}{*}{$\cdot, 1.1$} & $\cdot, \cdots 1$ & . ד., זr & $\varepsilon, Y_{T O}$ & الثابت \\
\hline & & & & & $\cdot, \cdots 1$ & $7,0 \mathrm{~V} \cdot-$ & .,$Y \leqslant Y-$ & البشري \\
\hline
\end{tabular}

يتبين من الجدول السابق وجود علاقة ارتباطية ذات دلالة إحصائية بين الأداء البشري

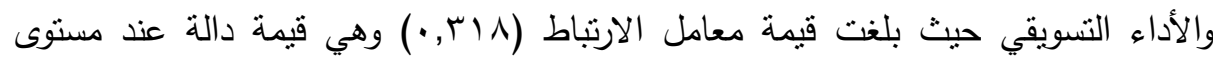
معنوية (0. (•)

بلغ معامل التحديد $\mathbf{R}^{2}$ (1 (1, •) وهو يعني أن التتبؤ بتأثثر الأداء البشري على الأداء

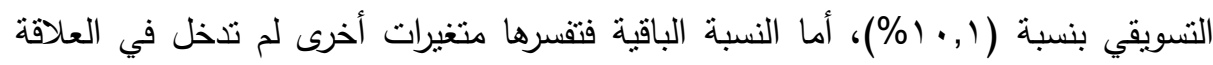

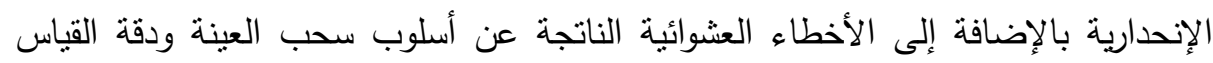
وغيرها، من خلال اختبار ت تبين أن قيمة (ت) وهي قيمة دالة معنوية عند مسنوى (0. . •)، 


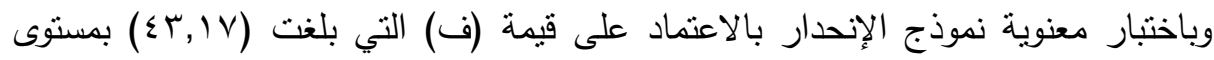

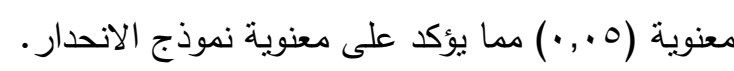
$\mathrm{Y}=\mathbf{4 . 2 3 5}+(-0.247) \quad \mathrm{X}$

مما سبق نرفض الفرض الثاني العدمي: لا يوجد تأثثر معنوي لمؤشرات تحقيق الأداء البشري على مؤشرات الأداء الأخرى في ضوء المنطلبات البيئية بالتطبيق على حديقة الحيوان بالجيزة.

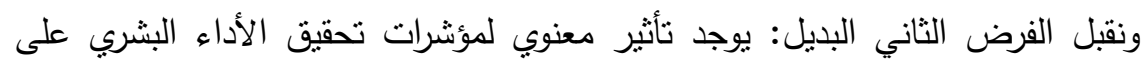
مؤشرات الأداء الأخرى في ضوء المنطلبات البيئية بالتطبيق على حديقة الحيوان بالجيزة. الفرض الثالث: لا يوجد تأثير معنوي لمؤثرات تقييم الأداء الفني على مؤثرات الأداء الأخرى في ضوء المتطلبات البيئية بالتطبيق على حديقة الحيوان بالجيزة.

\begin{tabular}{|c|c|c|c|c|c|c|c|c|}
\hline & & \multicolumn{7}{|c|}{ يدول (0): اختبار الإنحدار لتأثير الأداء الفني على الأداء المالي } \\
\hline 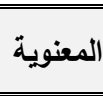 & 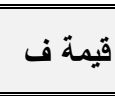 & المعياري & $\mathbf{R}$ & $\mathbf{R}^{2}$ & 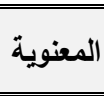 & قيمة ت & قيمة بيتا & المتغيرات \\
\hline \multirow{2}{*}{$\cdot, \cdots 1$} & \multirow[b]{2}{*}{ ro, } & \multirow[b]{2}{*}{$\cdot, \wedge 1$} & \multirow[b]{2}{*}{ - , YOY } & \multirow[b]{2}{*}{ זד., } & $\cdot, \ldots$ & YT,OVT & $11 K r, 009$ & الثابت \\
\hline & & & & & $\cdot, \cdots$ & $0, .9 r-$ & .,$Y \leq Y-$ & الفنداء \\
\hline
\end{tabular}

يتبين من الجدول السابق وجود علاقة ارتباطية ذات دلالة إحصائية بين الأداء الفني

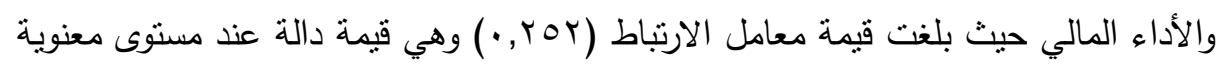
$\cdot(\cdot, \cdot 0)$

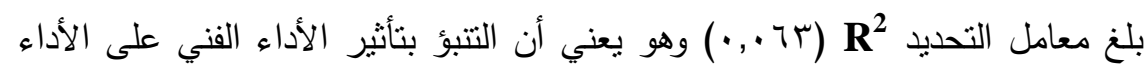

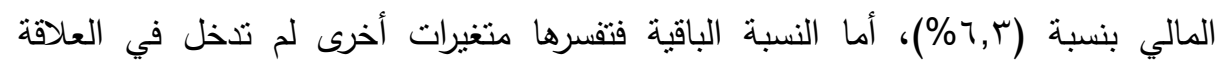

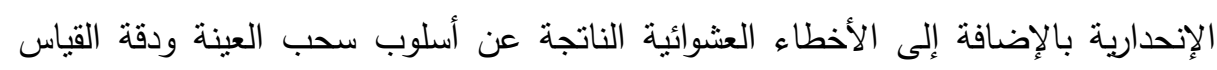

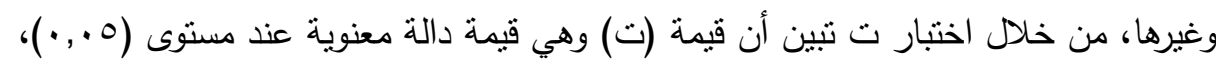

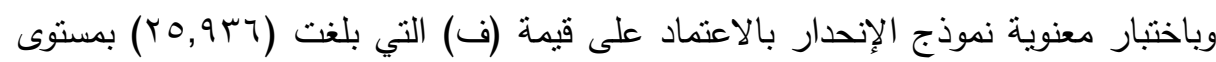

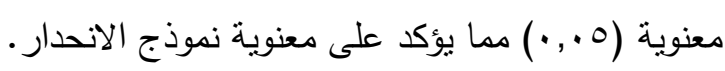
$Y=1123.6+(-0.246) \quad X$ 


\begin{tabular}{|c|c|c|c|c|c|c|c|c|}
\hline المعنوية & قيمة ف & الخعياري & $\mathbf{R}$ & $\mathbf{R}^{2}$ & المعنوية & قيمة ت & قيمة & لمتغيرات \\
\hline \multirow[b]{2}{*}{,,$\ldots l$} & \multirow[b]{2}{*}{$M, V \vee Y$} & \multirow[b]{2}{*}{ אז, } & \multirow[b]{2}{*}{ •, $\wedge$. } & \multirow[b]{2}{*}{ } & $\cdot, \ldots l$ & $r 1,9 \leqslant r$ & $r, \varepsilon O r$ & الثابت \\
\hline & & & & & $\cdot, \ldots 1$ & $r, O V \varepsilon-$ & , 170- & الألثراء \\
\hline
\end{tabular}

يتبين من الجدول السابق وجود علاقة ارتباطية ذات دلالة إحصائية بين الأداء الفني

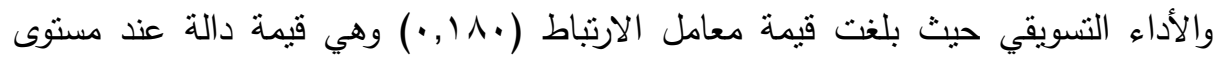
معنوية (0. (•).).

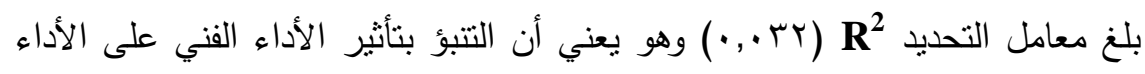

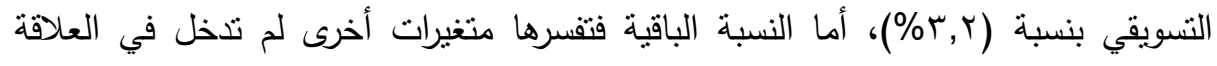
الإنحدارية بالإضافة إلى الأخطاء العشوائية الناتجة عن أسلوب سحب العابية العينة ودقة القياس

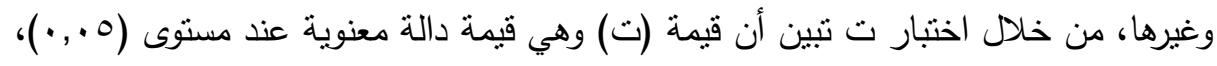

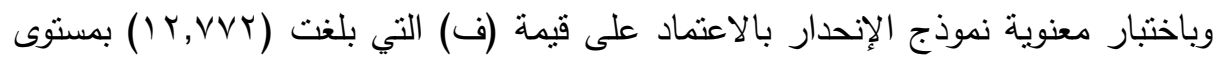

$$
\begin{aligned}
& \text { معنوية (0. . . •) مما يؤكد على معنوية نموذج الانحدار . } \\
& Y=(-3.452)+3.452 X
\end{aligned}
$$

\begin{tabular}{|c|c|c|c|c|c|c|c|c|}
\hline المعنوية & قيمة ف & المعياري & $\mathbf{R}$ & $\mathbf{R}^{2}$ & المعنوية & قيمة ت & قيمة & المتغيرات \\
\hline \multirow[b]{2}{*}{$\cdot, \ldots l$} & \multirow[b]{2}{*}{ 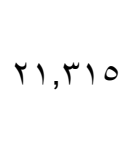 } & \multirow[b]{2}{*}{ • } & \multirow[b]{2}{*}{ • } & \multirow[b]{2}{*}{ r.,., } & $\cdot, \ldots)$ & $r \leqslant, 109$ & $r, 07 \pi$ & الثابت \\
\hline & & & & & $\cdot, \ldots 1$ & $\varepsilon, T) \vee-$ & $\begin{array}{r}- \\
\text {, YYq }\end{array}$ & القنى الأداء \\
\hline
\end{tabular}

جدول (V): اختبار الإنحدار لتأثنر الأداء الفني على الأداء البشري

يتبين من الجدول السابق وجود علاقة ارتباطية ذات دلالة إحصائية بين الأداء الفني

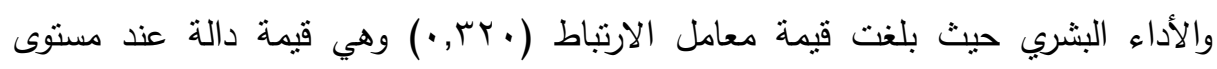
معنوية (0., (•) (•) 
بلغ معامل التحديد $\mathbf{R}^{2}$

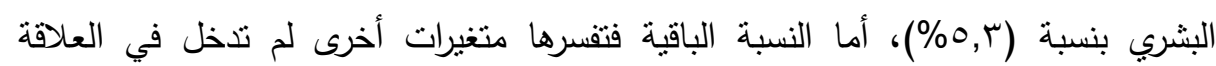

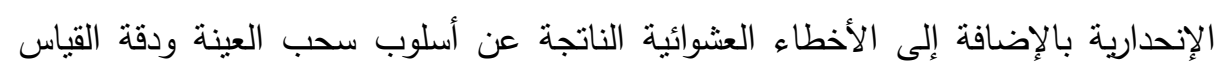

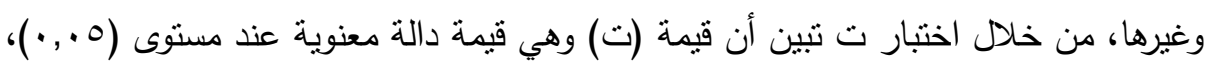

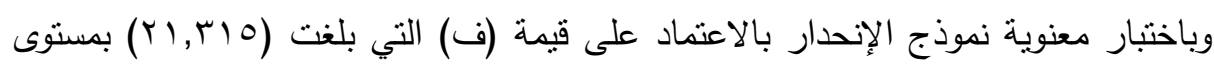

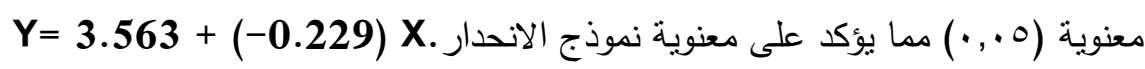
مما سبق نرفض الفرض الثالث العدمي: لا يوجد تأثنير معنوي لمؤشرات نقديبيم الأداء الفني على مؤشرات الأداء الأخرى في ضوء المتطلبات البيئية بالتطبيق على حديقة الحيوان بالجيزة. ونقبل الفرض الثالث البديل: يوجد ثأثنر معنوي لمؤشرات تقييم الأداء الفني على الأى مؤشرات الأداء الأخرى في ضوء المنطلبات البيئية بالنطبيق على حديقة الحيوان بالجيزة. الفرض الرابع: لا يوجد تأثثر معنوي لمؤشرات تحقيق الأداء التسويقي على مؤثرات الأداء الأخرى في ضوء المتطلبات البيئية بالتطبيق على حديقة الحيوان بالجيزة.

\begin{tabular}{|c|c|c|c|c|c|c|c|c|}
\hline المعنوية & قيمة & المعياري & $\mathbf{R}$ & $\mathbf{R}^{2}$ & المعنو & قيمة & قيبمة & المتغيرات \\
\hline \multirow{8}{*}{$\cdot, \cdot \varepsilon$} & \multirow{8}{*}{$0, \times 79$} & \multirow{8}{*}{$\varepsilon Y \leqslant 0 T r \varepsilon, q$} & \multirow{8}{*}{-, 9 १ А } & \multirow{8}{*}{$\cdot, \wedge 99$} & $\cdot, \cdot r$ & $\cdot, 9 \leq 9-$ & 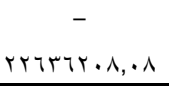 & الثابت \\
\hline & & & & & •, ६ & $1,19 \mathrm{~V}$ & 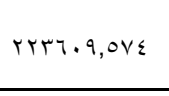 & بيانه من العداد ما تم \\
\hline & & & & & .,. \& & $r, \xi \mid A-$ & $|\varepsilon| r \wedge, q \vee 0-$ & بيعه من الريش أعاد تم \\
\hline & & & & & $\cdot, \mathrm{r}$ & $\cdot, 0 . V-$ & 1 $1 \leqslant V Y q$, roo- & بيعه من جلود أعاد تم \\
\hline & & & & &., .0 & $r, . \varepsilon$. & YTY, IVA & نثاط التصدير \\
\hline & & & & & $\cdot, \wedge$ & 正, & זצז & نشاط الاستيراد \\
\hline & & & & & $\cdot, \cdot r$ & r,VYT & . & المصريون \\
\hline & & & & &.,.$r$ & r,AYY- & $190, . . r-$ & الزائرون الأجاتب \\
\hline
\end{tabular}


يتبين من الجدول السابق وجود علاقة ارتباطية ذات دلالة إحصائية بين الأداء التسويقي

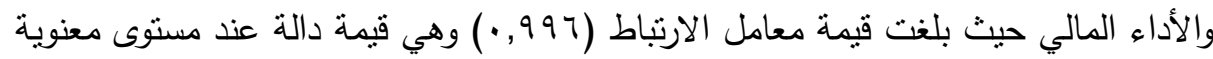
(0. . • •) واقتراب معامل الارتباط من الواحد الصحيح يدل على قوة هذه العلاقة. بلغ معامل التحديد

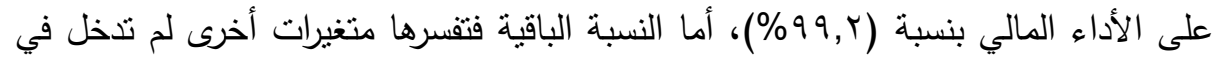
العلاقة الإنحدارية بالإضافة إلى الأخطاء العشوائية الناتجة عن أسلوب سحب الغباء العينة ودقة

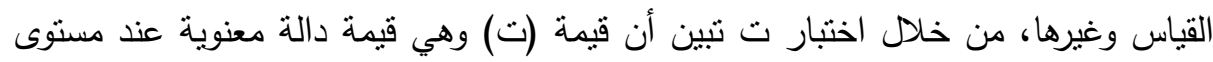

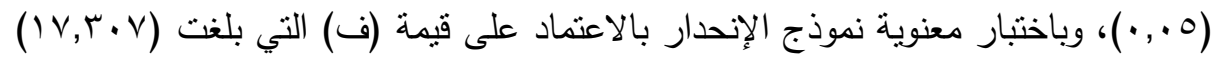
بمستوى معنوية (r ( , • ) مما يؤكد على معنوية نموذج الانحدار . (-8493.15) X2 + 426236.11X3+ +(-67842.40) X1 + Y= (-58466746.03) $(-22310.49) \mathrm{X} 4+(-657124.16) \mathrm{X} 4$

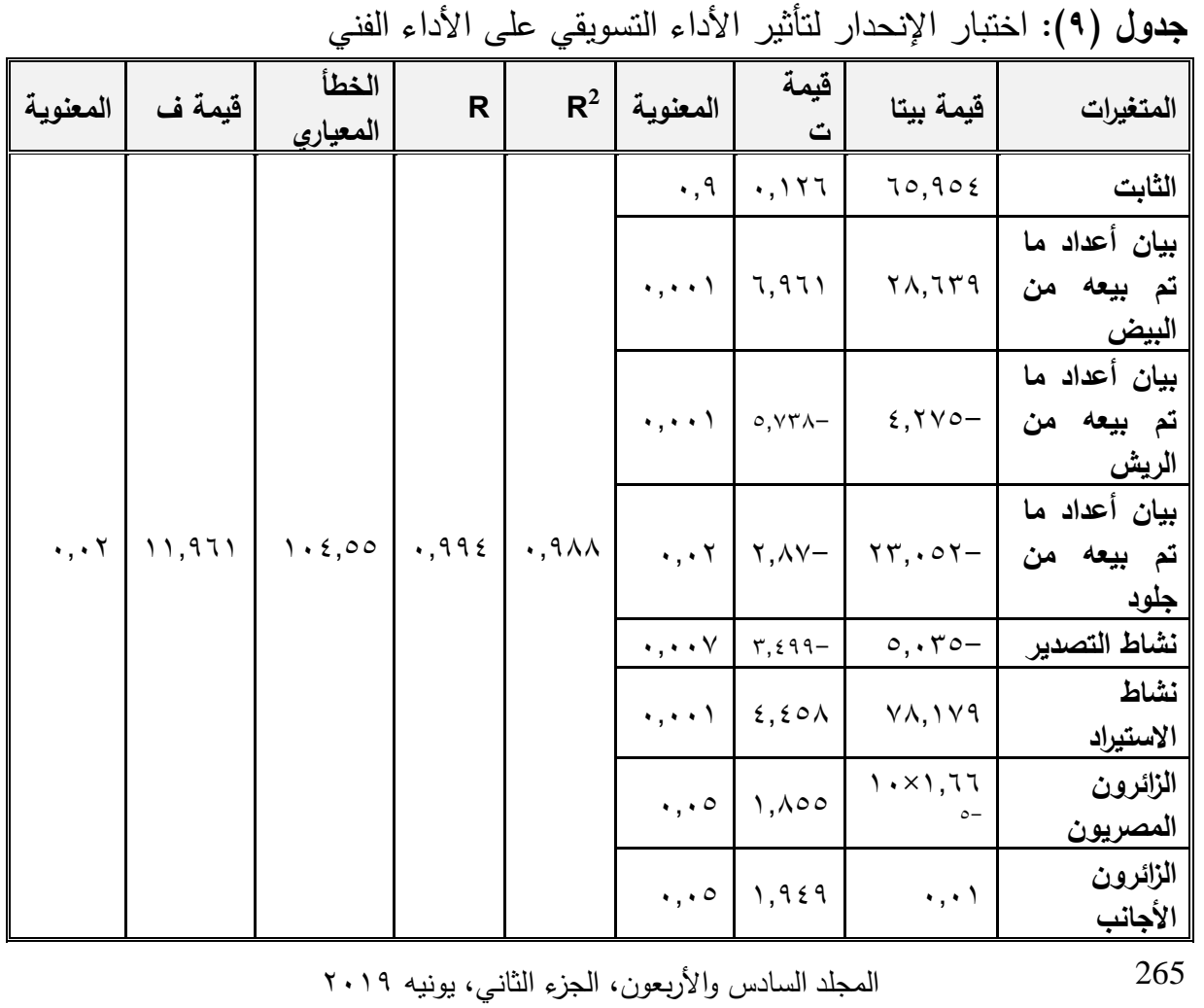


يتبين من الجدول السابق وجود علاقة ارتباطية ذات دلالة إحصائية بين الأداء التسويقي

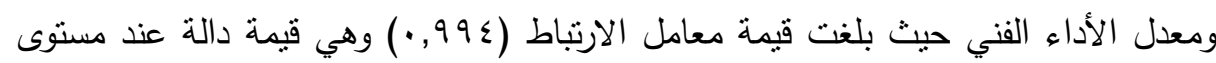
معنوية (0. . . ) واقتراب معامل الارتباط من الواحد الصحيح يدل على قوة هذه العلاقة. $\mathrm{X3}+(-5.035) \mathrm{X} 4+$ + )-23.052((-4.275) X2 + +28.639 X1 + Y= 65.954

78.179 X5 + 1.659 ×10 $10^{-5}$ X6 + 0.010X7 جدول (• (1): اختبار الإنحدار لتأثثير الأداء التسويقي على معدل الأداء البشري

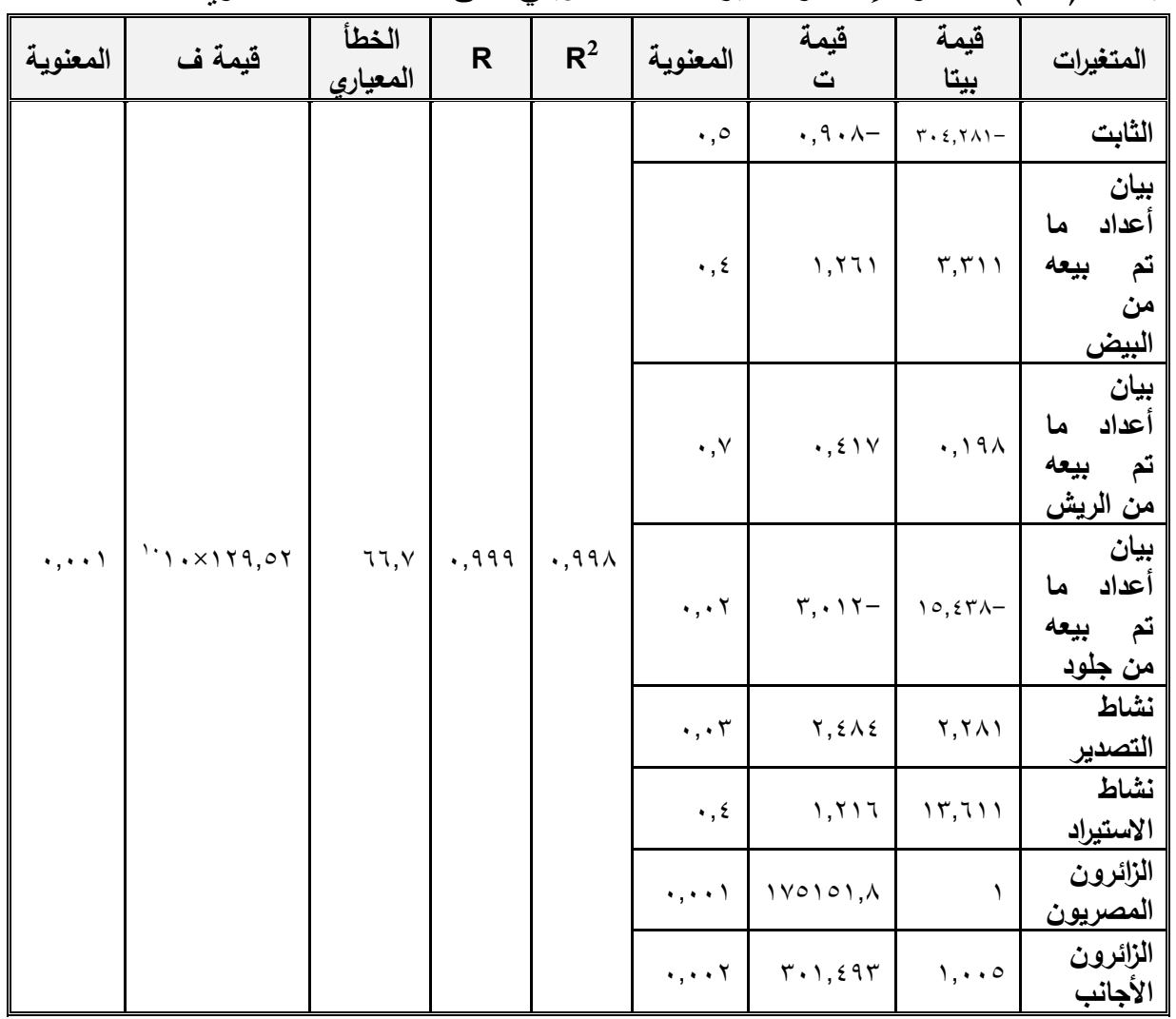

يتبين من الجدول السابق وجود علاقة ارتباطية ذات دلالة إحصائية بين الأداء التسويقي

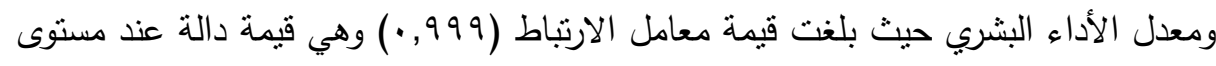
معنوية (0. . • ) واقتراب معامل الارتباط من الواحد الصحيح يدل على قوة هذه العلاقة. 
بلغ معامل التحديد

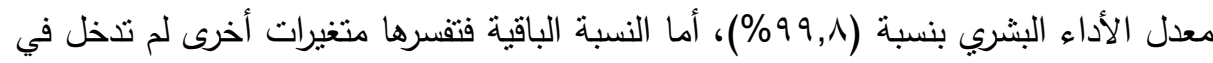

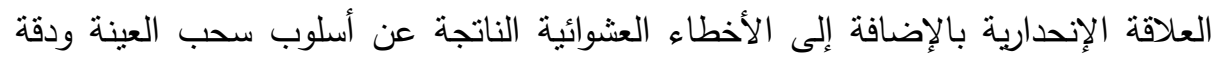

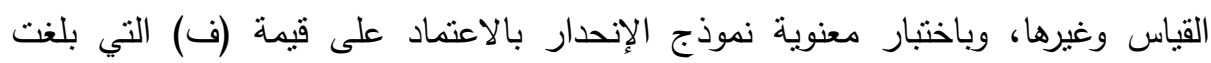

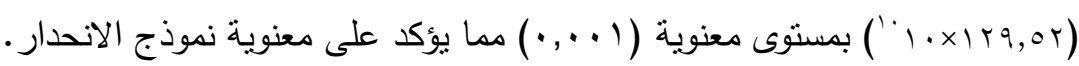

$\mathrm{X3}+\mathbf{2 . 2 8 1 X 4}+\mathbf{0 . 1 9 8} \mathrm{X} 2+(-15.438)+3.311 \mathrm{X} 1+\mathrm{Y}=(-304.281)$

\section{$1.000 \times 6+1.005 \times 7+13.611 \times 5$}

مما سبق نرفض الفرض الرابع العدمي: لا يوجد تأثثر معنوي لمؤشرات تحقيق الأداء التسويقي على مؤشرات الأداء الأخرى في ضوء المنطلبات البيئية بالنطبيق على حديقة

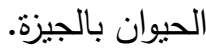

ونقبل الفرض الرابع البديل: يوجد تأثير معنوي لمؤشرات تحقيق الأداء التسويقي على التى مؤشرات الأداء الأخرى في ضوء المتطلبات البيئية بالتطبيق على حديقة الحيوان بالجيزة.

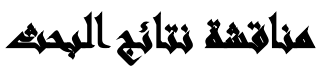

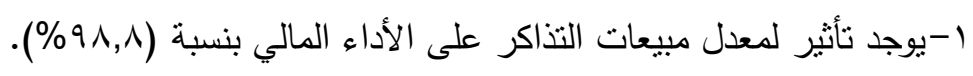

r-تم رفض الأول العدمي: لا يوجد تأثثر معنوي ذو دلالة إحصائية لمؤشرات تحقيق الأداء

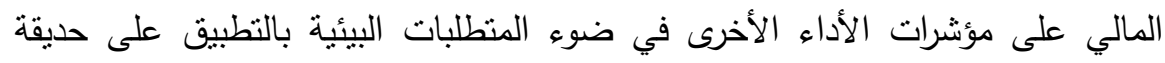

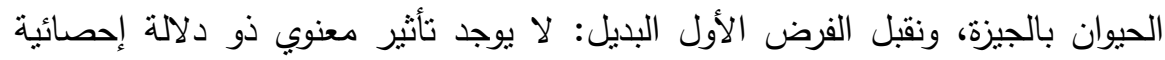
لمؤشرات تحقيق الأداء المالي على مؤشرات الأداء الأخرى في ضوه الهيء المتطلبات البيئية بالتطبيق على حديقة الحيوان بالجيزة.

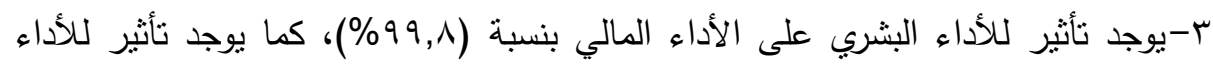

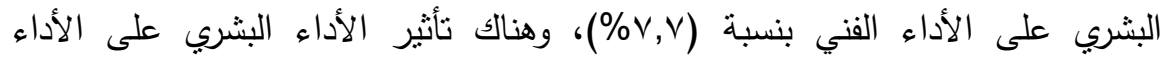

$$
\text { التسويقي بنسبة (1, •(1\%). }
$$


ع-تم رفض الفرض الثاني العدمي: لا يوجد نأثير معنوي لمؤشرات تحقيق الأداء البشري

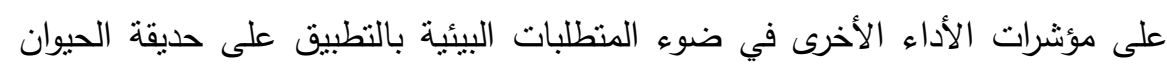

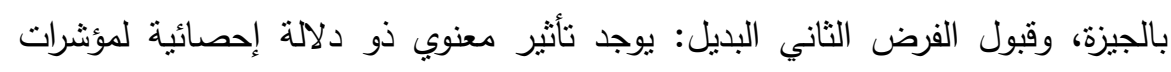

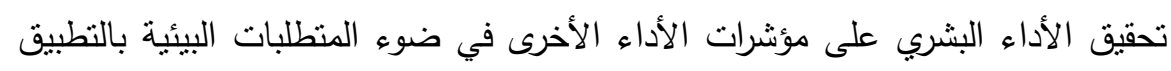
على حديقة الحيوان بالجيزة.

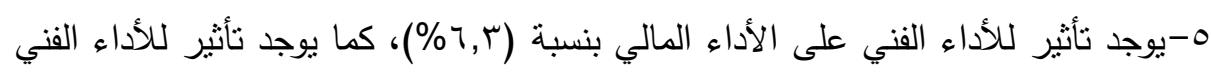

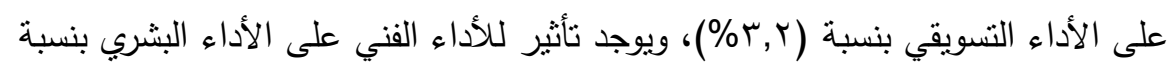
. $(\% 0, \Gamma)$

צ-تم رفض الفرض الثالث العدمي: لا يوجد تأثنر معنوي لمؤشرات تقييم الأداء الفني على

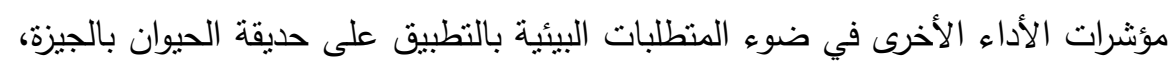

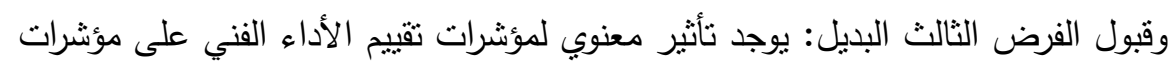
الأداء الأخرى في ضوء المتطلبات البيئية بالتطبيق على حديقة الحيوان بالجيزة.

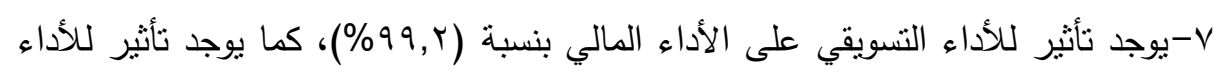

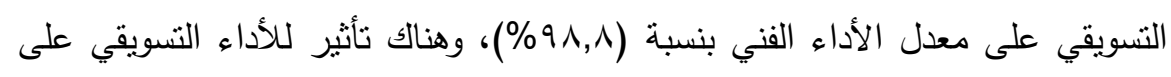
معدل الأداء البشري بنسبة (19,^99\%).

1-مما سبق نرفض الفرض الرابع العدمي: لا يوجد تأثنير معنوي لمؤشرات تحقيق الأداء

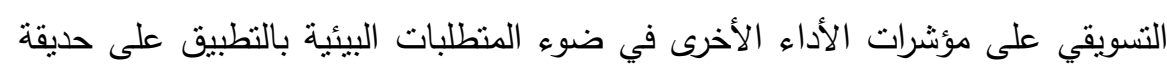

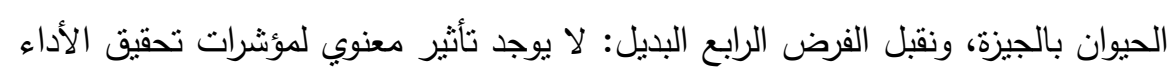

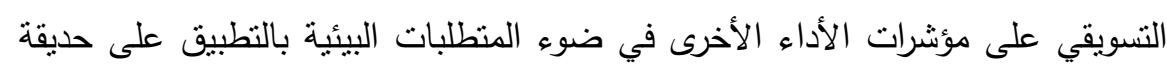
الحيوان بالجيزة.

\section{تموسياهت المهيد}

() بذل الجهود لتحسين كيفية تتفيذ الإدارة البيئية بطريقة جيدة في الحديقة ودمجها مع مقاييس

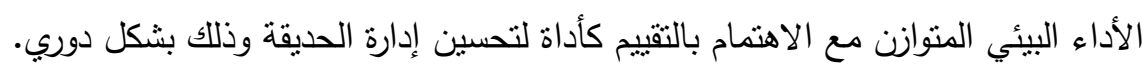


r) الاهتمام بزيادة الوعي البيئي لاى الزائرين مع فرض عقوبات شديدة جداً ضد المخربين

$$
\text { لمنشآت الحديقة. }
$$

r) زيادة مستوى الخدمات الموجودة والمقدمة للزائرين.

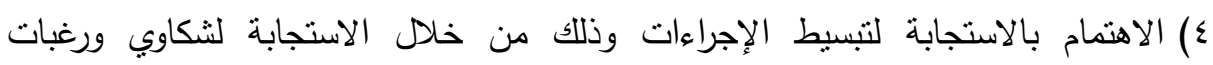

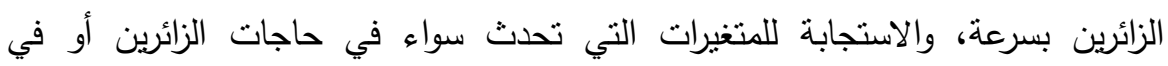

$$
\text { الظروف المحيطة بصفة عامة للحديقة. }
$$

0) العمل على نطوير قدرات العاملين من خلال إقامة الدورات التدريبية وفق أحدث البرامج التدربيية في مجال الأداء البيئي فيما ينعكس إيجاباً في تحسين الأداء ووضع ألعان أفكار العاملين واهتماماتهم محل الاهتمام والتطبيق.

\section{المرالم}

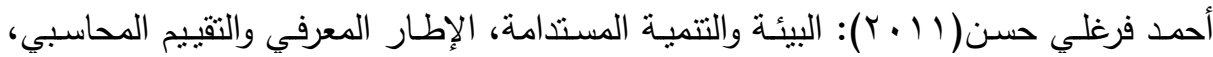
مركز تطوير الدراسات العليا

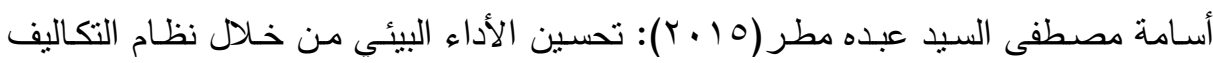

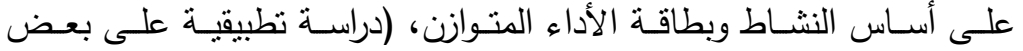

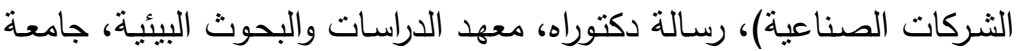

$$
\text { عين شمس }
$$

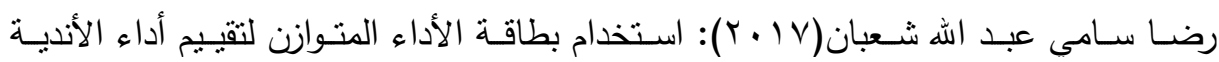

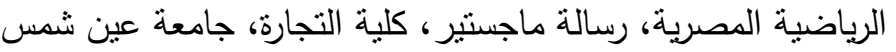

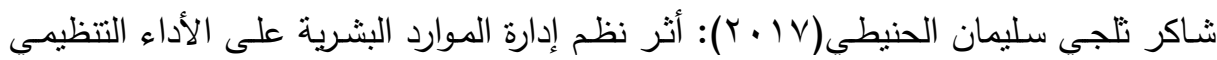

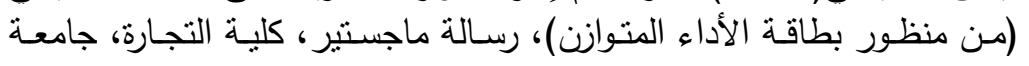

$$
\text { عين شمس منظور }
$$

منسى حسن حجازي عبد الفتاح(10 ب ب): استخدام موازنـة البرامج والأداء في التقيبم البيئي

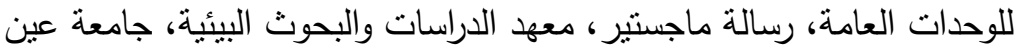

شمسن 


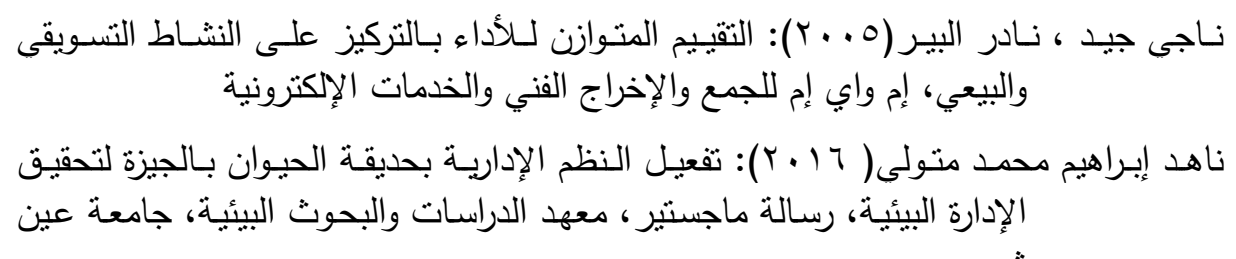

A. Mallapur \& A. Ramanathan. Diffierences in husbandry and management systems across ten facilities housing Asian elephants Elephas maximas in India. Journal compilation The Zoological Society of London The Authors.int, zoo yb 2009

Christina A. Alligood Katherine A. Leighty. Nicole R. Dorey Lindsay R. Mehrkam, Applying behavior-analytic methodology to the science and pradtice of environmental enrichment in zoos and aquariums Disney's Animal Kingdom, Lake Buena Vista, Florida,. University of Florida, Gainesville, Florida. 3- Monmouth University, West Long Branch, New Jersey. Wileyonlinelibrary. Com/journal/zoo. 2017

Laurence, M. Measuring Financial Performance: A Critical Key to Managing Risk, National Crop Insurance Services, Inc. (2011).

Naim AFGAN, Dejan CVETINOVIC and Paul ANDRE, Sustainable Resilience of Company Management System Categorized Economics, volyume 1 Issue no. 7, Knowledge Management, Posted on 15 December 2011.

Turner. Measuring performance: environmental management systems. International Zoo Yearbook Journal compilation the zoological society of London volume 43. Issue. 1. January 2009.

Wang, L., Corporate Performance Efficiency Envelopment Analysis \& Balanced Scorecard Journal of American Academy of Business Cambridge, Vol. 9. No, 2, 2006.

$$
\text { المجلد السادس والأربعون، الجزء الثاني، يونيه } 19 \text { ب ا }
$$


Zhu, Y., Guo, D., Wang. D., Li, J. How to find environmental risk factors of Zoonotic infectious disease quickly. (2016). Proceedings of the $2^{\text {nd }}$ ACM SIGSPATIAL international Workshop on the Use of GIS in Emergency Management, EMGIS 2016.

\title{
A PROPOSED MODEL FOR ACHIEVING BALANCE SCORE CARD IN GIZA IN TERMS OF THE ENVIRONMENTAL REQUIREMENTS A COMPARATIVE STUDY WITH DUBAI ZOO
}

\section{Nahid I. M. Metwaly ${ }^{(1)}$; Nader A. Fanous ${ }^{(2)}$} and Mahmoud A. M. Ameen ${ }^{(2)}$

1) Post grad., Institute of Environmental Studies \& Research, Ain Shams University 2) Faculty of Commerce, Ain Shams University

\begin{abstract}
Probably, the climate change has a critical impact on biological variation, and actually, the modernist zoos are concerned with largely with the protection of the biological variation and conserving the extinction-threatened animals; so, there should be an obligation to reduce impacts affecting the environment, particularly, their contribution in the factors leading to climate change. Environmental management system considers a specific tool for determining, measuring, and reducing the impact of the zoo on the environment in a regular way. In order to describe the situation as well-ordered, the environmental performance level should be elevated and there should be a research circular method consisting of four stages "plans-execution - review - Action" .added to that deep rooting the international

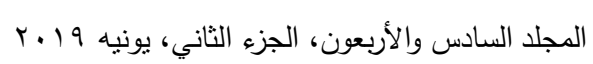


standard ISO 14001 system that concerns the environment's management (Turner, 2009). This research significance is crystallized in demonstrating dimensions of performance and (financial-humantechnical-marketing) balance and its impact on achieving environmental demands. This research's objective is to achieve balanced performance in Giza zoo in terms of the environmental requirements compared to Dubai zoo. The data concerning the financial, human, technical, and marketing performance are collected from reports and information involved in selling-tickets rate, the training budget, and range of application of the environmental management systems in the central management in both the Giza Zoo and Dubai Zoo. The research hypotheses indicate a significant statistically correlation between indicators of the financial, technical, human and marketing performance in light of the environmental demands. The analytical analysis is used to form the theoretical framework and data is collected through examining the Giza zoo as a case study. Results indicate a statistically significant effect of the financial performance at $(0,05)$ significance level and a statistically significant effect of the technical performance at (0.05) significance level. There is also a statistically significant effect of marketing performance at (0.05) significance level. The research recommends holding training programs for employees concerning application of the environmental management system. 